\title{
РАСТИТЕЛЬНЫЕ СУКЦЕССИИ НА ОТВАЛАХ УГОЛЬНЫХ ШАХТ В ЛЕСОСТЕПИ ТУЛЬСКОЙ ОБЛАСТИ
}

\author{
(С) 2020 г. С. А. Леднев ${ }^{a, ~ * ~, ~ А . ~ В . ~ Ш а р а п о в а ~}{ }^{a}$, И. Н. Семенков ${ }^{a}$, Т. В. Королева ${ }^{a}$ \\ ${ }^{a}$ Московский государственный университет имени М.В. Ломоносова, географический факультет, Москва, Россия \\ *e-mail sled1988@mail.ru \\ Поступила в редакцию 18.02.2019 г. \\ После доработки 18.02.2019 г. \\ Принята к публикации 28.11.2019 г.
}

\begin{abstract}
Описаны сукцессии растительности, наблюдаемые на угольных отвалах Подмосковного буроугольного бассейна (ПБУБ). Выполнены геоботанические описания на нерекультивированном терриконе, спланированном отвале и фитомелиорированном терриконе. Зарастание отвалов угледобычи представляет собой пример первичной сукцессии, протекающей в специфических эдафических условиях. Скорости самовосстановления растительности на отвалах ПБУБ в Тульской области различаются на разных объектах. Наиболее медленно зарастают склоны терриконов и спланированных отвалов, где встречаются только одиночные пионерные особи рудеральных видов растений. На спланированной поверхности отвалов и стихийно развивающихся делювиально-пролювиальных шлейфах формируются пионерные группировки, простые и сложные фитоценозы. Наиболее распространенной древесной породой в простых и сложных фитоценозах является Betula pendula. Под воздействием токсичных стоков на делювиально-пролювиальных шлейфах и в отдельных частях спланированных отвалов травяно-кустарничковый ярус сложен главным образом Calamagrostis epigeios, Equisetum spp., Convolvulus arvensis. Вне влияния токсичных стоков на спланированном отвале образуются разнотравные фитоценозы со значительным участием бобовых (Trifolium hybridum, Lotus corniculatus, Melilotus albus и др.). Фитомелиорация на объектах ПБУБ в Тульской области значительно ускоряет процесс самовосстановления, минуя продолжительную стадию пионерных группировок. Разработана схема протекания процессов самозарастания отвалов ПБУБ в лесостепных ландшафтах.
\end{abstract}

Ключевые слова: самовосстановление растительности, первичная сукцессия, угольные отвалы, техногенные экосистемы, растительные сообщества, рекультивация отвалов

DOI: $10.31857 / \mathrm{S} 2587556620020089$

\section{ВВЕДЕНИЕ}

Во многих регионах Российской Федерации актуальным вопросом является возможность повторного использования территорий, выведенных из хозяйствования, что связано с высокой плотностью населения и большим количеством производств, занимающих значительное пространство и по разным причинам не функционирующих. В Ленинградской, Новгородской, Тверской, Смоленской, Московской, Калужской, Тульской и Рязанской областях таковой является инфраструктура шахт ПБУБ, включающая в себя собственно шахты, терриконы, отвалы и т.п., где к настоящему времени угледобыча прекращена.

Специфика шахтной добычи угля связана с формированием отвалов и терриконов. Кроме того, в результате подземной добычи угля над горными выработками формируются просадки грунта [1]. Появление техногенных объектов оказывает воздействие на природные ландшафты.
Как правило, на поверхности терриконов и отвалов процесс самовосстановления растительности (сукцессия) сильно растянут во времени вследствие неблагоприятного водного режима, токсичного воздействия сульфидсодержащих пород, сильного нагрева склонов инсолируемых экспозиций, жесткого ветрового режима и т.п. [4, 7]. Хотя поселение пионерных видов на отвалах отмечается уже на первый год после отсыпки, в зависимости от размеров отвала естественное зарастание может начинаться через 15-30 лет после вывода из эксплуатации, а переход к стадии зональной растительности не наблюдается даже на 50-летних и более старших отвалах [5]. Рекультивация промышленных отвалов с созданием культурных фитоценозов существенно ускоряет самовосстановление растительности [11]. Однако на отвалах ПБУБ в Тульской области рекультивация проведена на сравнительно небольшом числе объектов и в подавляющем большинстве случаев 
ограничивается засыпкой выработанного пространства карьеров вскрышными породами. Темпы и качество такой рекультивации крайне низки [1]. В большинстве случаев растительность на терриконах и отвалах восстанавливается медленно в процессе самозарастания отдельных участков.

Исследование самовосстановления растительности на отвалах угледобывающих предприятий имеет большое значение для разработки эффективных и рациональных методов рекультивации $[7,11]$. Естественное зарастание отвалов изучали в различных регионах и природных зонах России, но больше работ посвящено Кузнецкому угольному бассейну $[4,5,8]$, отвалам угольных месторождений в лесостепи в Красноярском крае [6] и Республике Тыва [10]. Подобные исследования за рубежом проводили в Китае [14, 15], Монголии [3], в странах Восточной Европы [13] и других регионах мира. На этом фоне исследования восстановления растительности на объектах ПБУБ представлены скудно [7]. При этом протекающие в ПБУБ природные процессы характеризуются определенным своеобразием ввиду прекращения в настоящее время угледобычи, значительного возраста отвалов, высокой токсичности и сравнительно низкой горючести углесодержащих пород [12], наблюдаемого саморазвития техногенно созданных ландшафтов без проведения фитомелиорации и других факторов.

Целью данной работы является детальный анализ хода самовосстановления растительности ландшафтов терриконов и отвалов ПБУБ, расположенных в пределах лесостепи Тульской области.

\section{МАТЕРИАЛЫ И МЕТОДЫ}

Материал собран на территориях Киреевского и Узловского районов Тульской области, где шахтная угледобыча проводилась главным образом в период до 1980-начала 1990-х годов. В качестве модельных объектов выбраны:

- нерекультивированный террикон шахты № 2 “Киреевская” в 2 км к юго-западу от д. Ильинка;

- спланированный отвал на месте бывшего Киреевского разреза возле шахты "Владимировская”, в 1 км к юго-западу от г. Киреевск;

- террикон шахты № 12 в 300 м к юго-западу от

д. Синяевка, фитомелиорированный в 2015 г.

Стадии самовосстановления (стадии сукцессии) растительности выделены по [4, 7]:

1. Пионерные группировки: мозаичный растительный покров, представленный видами широкой экологической амплитуды, обладающих высокой способностью к воспроизводству;

2. Простой фитоценоз: многовидовое сообщество с проявлением зональных черт, усложненной структурой, увеличением роли многолетников;
3. Сложный фитоценоз: экологическая дифференциация состава флоры, преобладание многолетников, выраженные зональные черты.

Стадии сукцессии растительности на исследованных объектах определены и охарактеризованы на основании геоботанических описаний, проведенных по стандартной методике [2] на пробных площадках размером $10 \times 10$ м. Описан видовой состав, у растений определены проективное покрытие, высота и фенофаза.

\section{РЕЗУЛЬТАТЫ И ОБСУЖДЕНИЕ}

Изученные объекты значительно отличаются по условиям возобновления растительности. Крутизна склона может варьировать от практически выположенной поверхности (у подножия терриконов или на спланированных отвалах) до $45^{\circ}-50^{\circ}$ и более. В зависимости от крутизны склона могут значительно изменяться эдафические условия, кислотность и влажность субстрата [12].

1. Нерекультивированные терриконы. Бо́льшая часть поверхности нерекультивированных терриконов и краевые склоны спланированных при рекультивации отвалов представляют собой наименее подходящие местообитания вследствие значительного содержания токсичных веществ и большой крутизны склона. В результате даже спустя десятилетия после окончания отсыпки в подавляющем большинстве случаев эти объекты лишены какой-либо растительности. Изредка на их поверхности можно обнаружить одиночные особи пионерных видов деревьев - березы повислой (Betula pendula), ивы козьей (Salix caprea), клена ясенелистного (Acer negundo) и др., в основном в ювенильном и имматурном состоянии. Травянистые пионеры встречаются реже; как правило, это рудеральные однолетники и многолетники: горец птичий (Polygonum aviculare), пырей ползучий (Elytrigia repens), лебеда раскидистая (Atriplex patula) и др., характерные для инициальных стадий. Общее проективное покрытие (ОПП) травянистых растений не достигает $1 \%$. Как правило, растения на склонах терриконов приурочены к выположенным участкам с наименьшим содержанием соединений серы и других токсичных элементов, в том числе к участкам выгорания породы, выделяющимся более светлой окраской.

Интенсивнее зарастают делювиально-пролювиальные шлейфы, формирующиеся по периферии тела террикона вследствие оползней и размыва поверхности дождевыми и талыми водами. Здесь обычно встречаются пионерные группировки, представленные видами, наиболее устойчивыми к влиянию вымываемых из породы токсичных веществ. Характерны вьюнок полевой (Convolvulus arvensis), хвощ лесной (Equisetum syl- 
vaticum), хвощ полевой (E. arvense), вейник наземный (Calamagrostis epigeios), ежовник обыкновенный (Echinochloa crus-galli); наиболее характерным древесным растением является береза повислая (Betula pendula). Разреженные пионерные группировки могут быть удалены на десятки метров от подошвы террикона. Видовая насыщенность их, как правило, не превышает 10 видов на $100 \mathrm{~m}^{2}$, ОПП составляет порядка $10 \%$.

Стадия простого фитоценоза на шлейфах терриконов, как правило, представлена луговыми или лесными вариантами, значительно отличающимися друг от друга. Соответственно, переход из стадии пионерных группировок к простому фитоценозу происходит либо за счет интенсивного разрастания вейника, либо за счет развития закрепившихся особей березы в условиях практически полного отсутствия травянистых растений. Луговые сообщества представляют собой преимущественно монодоминантные вейниковые фитоценозы с очень низкой флористической насыщенностью (3-4 вида на $100 \mathrm{~m}^{2}$.). Подрост березы немногочисленный и разновозрастный; можно предположить, что смена вейникового фитоценоза березняком, занимающая в обычных условиях порядка 6-7 лет [9], на делювиальнопролювиальных шлейфах террикона протекает медленнее.

В свою очередь, лесные сообщества на шлейфах представлены березняками со сравнительно высокой сомкнутостью крон (50-60\%) и незначительной примесью других пионерных пород осины (Populus tremula), ивы козьей (Salix caprea), клена ясенелистного (Acer negundo) и др. Сомкнутый древостой здесь формируется постепенно за счет удачного развития единичных особей, не погибающих под воздействием токсичных стоков с террикона. На это указывает большое количество проростков и ювенильных особей березы (возрастом менее 1 года), а также значительная разновозрастность деревьев в составе подроста и древостоя. Травяно-кустарничковый ярус в данных сообществах, как правило, соответствует стадии пионерных группировок, а в ряде случаев полностью или практически полностью отсутствует; флористическая насыщенность травяно-кустар-

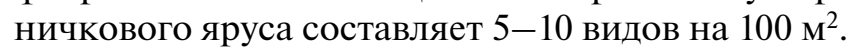

Описанные типы простых фитоценозов отличаются друг от друга не только по характерному габитусу, но и по приуроченности к различным участкам шлейфов. Ближе всего к террикону, как правило, находятся лесные варианты фитоценозов, приуроченные к крупным делювиально-пролювиальным шлейфам и нередко подступающие к подошве террикона. Вейниковые сообщества располагаются по окраине шлейфов и, вероятно, являются одним из факторов, сдерживающим распространение токсичного материала на при- легающую территорию: большая густота стояния побегов задерживает частицы выносимой породы. На границе этих сообществ в периферийных частях шлейфа возможно формирование "переходного” варианта березняка со значительным участием вейника в травяно-кустарничковом ярусе.

При длительном существовании на шлейфе вейниковых сообществ или березняка в условиях ослабления стока с террикона происходит переход к стадии сложного фитоценоза - мелколиственного леса, сложенного главным образом березой повислой с примесью других мелколиственных пород. ОПП травяно-кустарничкового яруса составляет не менее 50\%, видовая насыщенность превышает 30 видов на 100 м². При наличии кислотных стоков с террикона в травяно-кустарничковом ярусе может преобладать вейник, но по мере их ослабления на позиции доминантов и субдоминантов выходят типично луговые и луговоопушечные виды, такие, как земляника лесная (Fragaria vesca), пижма обыкновенная (Tanacetum vulgare), подорожник средний (Plantago media), тысячелистник обыкновенный (Achillea millefolium), донник белый (Melilotus albus), подмаренник настоящий (Galium verum) и др. По всей видимости, формируется этот тип фитоценоза в результате возобновления березы на вейниковых лугах либо при постепенном задерновывании березняков на отдельных участках шлейфов.

2. Спланированные отвалы. В условиях минимальной рекультивации объектов ПБУБ, заключающейся в формировании спланированных отвалов на местах бывших открытых разрезов, возобновление растительности протекает быстрее, чем на неспланированных объектах. Более успешному зарастанию способствует менее интенсивный смыв образующегося органического вещества с выровненной поверхности отвала.

Стадия пионерных группировок наблюдается на пологих склонах и бровках по краю отвалов. Пионерные виды поселяются главным образом вне областей активного размыва углесодержащей породы. ОПП растительности на этой стадии не превышает 10-20\%, видовая насышенность со-

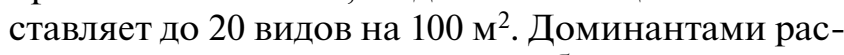
тительного покрова главным образом являются рудералы и виды широкой экологической амплитуды: мятлик узколистный (Poa angustifolia), вейник наземный (Calamagrostis epigeios), щавелек малый (Rumex acetosella) и др. Наравне с ними наибольших значений ОПП достигают бобовые: клевер гибридный (Trifolium hybridum), лядвенец рогатый (Lotus corniculatus), люцерна хмелевидная (Medicago lupulina), донник белый (Melilotus albus) и др., которые не представлены на стадии пионерных группировок на нерекультивированных терриконах. На выположенной поверхности делювиально-пролювиального шлейфа не наблю- 
дается значительного участия бобовых вследствие постоянного воздействия кислых стоков с расположенного рядом террикона, тогда как на выположенной поверхности отвала, наоборот, уменьшается кислотность субстрата в отсутствии вноса новых кислотных соединений.

Стадия простого фитоценоза на спланированном отвале представляет собой двухъярусное сообщество. Древесный ярус представлен главным образом подростом березы повислой, значительно более массовым и однородным по возрасту в сравнении с делювиально-пролювиальными шлейфами терриконов. В травяно-кустарничковом ярусе с ОПП до 40\% насчитывается до 20-30 видов на 100 м $^{2}$. При этом в травостое преобладают либо злаки (преимущественно вейник), либо бобовые (аналогичны описанным на стадии пионерных группировок). Распределение этих вариантов растительности по поверхности отвала неоднородно и, по всей видимости, связано с временными водотоками, обеспечивающими плоскостной смыв углесодержащей породы. В областях сосредоточения таких водотоков, по сути напоминающих шлейфы, преобладают сообщества с доминированием вейника; на участках, где выраженные следы плоскостного смыва отсутствуют, как правило, преобладают бобовые.

В наиболее старых частях отвала растительный покров находится в стадии сложного фитоценоза, структура и видовой состав которого в целом аналогичны сложному фитоценозу нерекультивированных терриконов. Однако, по всей видимости, в условиях спланированного отвала переход к данной стадии протекает значительно быстрее вследствие более массового развития подроста березы.

3. Фитомелиорированные терриконы. На единичном терриконе в районе исследования выполнена фитомелиорация с планированием поверхности, нанесением плодородного слоя почвы и созданием системы дренажных канав. Спустя 1 год на поверхности террикона сформировался луговой культурный фитоценоз (ОПП 70\%) с преобладанием клевера лугового (Trifolium pratense) и латука компасного (Lactuca serriola) и участием мятлика лугового (Poa pratensis), костреца безостого (Bromopsis inermis) и др. Видовой состав фитоценоза несколько отличается от фоновых луговых сообществ значительной долей рудеральных видов, что характерно для восстанавливающегося сообщества после механических нарушений почв.

Основываясь на литературных данных по фитомелиорации золоотвалов ГРЭС [11], в ближайшие несколько лет на теле террикона можно ожидать стабилизацию видового состава с уменьшением доли рудералов, выпадением части подсеянных видов (например, овес посевной (Avena sativa)) и заселением отсутствующих в настоящий момент природных видов (например, морковь дикая (Daucus carota)), репешок обыкновенный (Agrimonia eupatoria) и др.). В результате произойдет формирование устойчивого лугового сообщества, соответствующего стадии простого фитоценоза. Проводимая биологическая рекультивация значительно ускоряет восстановление растительности, минуя стадию пионерных группировок.

\section{ОБСУЖДЕНИЕ}

Результаты зарастания терриконов, с одной стороны, в целом соответствуют описанным ранее [4, 5, 7 и др.]. С другой стороны, различные варианты хода самовосстановления и флористический состав растительных сообществ на разных стадиях этого процесса являются следствием своеобразия объектов ПБУБ и района исследований.

Динамические ряды растительности на поверхности спланированных отвалов и делювиально-пролювиальных шлейфов можно считать примерами первичных сукцессий [3]. При этом стадия напочвенных водорослей, мохообразных и лишайников практически отсутствует ввиду высокой чувствительности видов данных систематических групп к химическому воздействию среды.

По результатам наблюдений составлена схема протекания процессов самовосстановления растительности на шлейфах терриконов и спланированных отвалах ПБУБ лесостепной зоны (рис. 1).

Стадии пионерных группировок на шлейфах и телах терриконов в целом сходны, но отличаются наличием на шлейфах варианта сообщества без травяно-кустарничкового яруса при сильном угнетении токсичными веществами. Видовой состав отражает разницу в токсичности субстрата, на котором развиваются группировки. В дальнейших вариантах как для шлейфов терриконов, так и для спланированных отвалов выделяются “вейниковый” и “разнотравный” пути развития.

“Вейниковый” вариант в общих чертах одинаков для обеих структур терриконов: на стадии простого фитоценоза формируется луговое сообщество с доминированием вейника наземного (Calamagrostis epigeios), характерное для областей с постоянным привносом токсичных веществ с тела террикона. По мере разрастания вейниковых зарослей на участках, где снижено токсичное воздействие, приживаются всходы березы, в результате чего вначале формируется редкостойный вейниковый березняк, а затем (при увеличении сомкнутости крон в древесном ярусе) в травянокустарничковом ярусе - лугово-опушечное разнотравье.

“Разнотравные” варианты простых фитоценозов на спланированных отвалах и шлейфах терриконов имеют отличия: на доминирующие пози- 


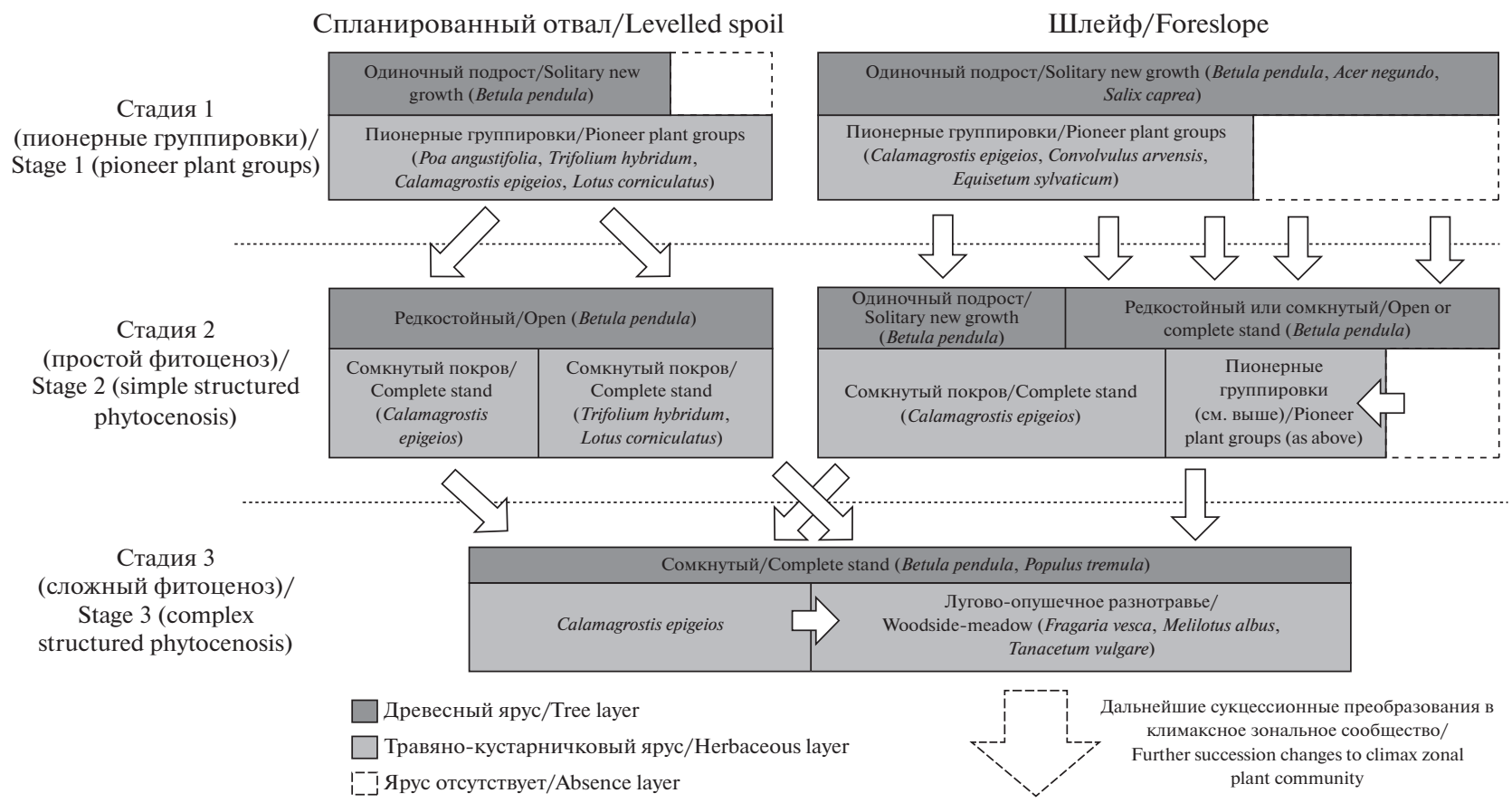

Рис. 1. Предположительная схема первичных сукцессий растительности на спланированных отвалах и шлейфах терриконов ПБУБ в пределах лесостепи Среднерусской возвышенности. В скобках указаны характерные виды яруса.

ции выходят виды из семейства бобовые, что характерно для бедных субстратов, где они обладают конкурентным преимуществом ввиду ризобиального симбиоза с азотфиксирующими бактериями.

В свою очередь, на шлейфах при продолжающемся привносе токсичных веществ развитие травяно-кустарничкового яруса нередко затормаживается, и видовой состав практически не меняется со стадии пионерных группировок. Своеобразие данного пути развития заключается в смыкании древесного яруса, сложенного березой на стадии простого фитоценоза. Со временем накапливается гумус и постепенно развивается травяно-кустарничковый ярус, в котором виды, устойчивые к повышенной токсичности, сменяются видами лугово-опушечного разнотравья. Финальным вариантом растительности как на шлейфах, так и на телах терриконов являются мелколиственные леса с лугово-опушечным разнотравьем в травяно-кустарничковом ярусе, в большей или меньшей степени соответствующие вторичным лесам на местах гарей, вырубок и т.п. Дальнейшее развитие данных сообществ в виду перекрытия толщи углесодержащей породы и ее химической и биологической трансформации, вероятно, должно двигаться по общим зональным закономерностям лесных сукцессий, но, скорее всего, данный процесс будет замедлен ввиду маломощности плодородного слоя почвы.

\section{ЗАКЛЮЧЕНИЕ}

Наиболее активные процессы самозарастания на отвалах ПБУБ в Тульской области наблюдаются на выположенных поверхностях терриконов и делювиально-пролювиальных шлейфов. Под влиянием токсичных стоков с террикона на делювиально-пролювиальных шлейфах отмечаются более низкие значения флористической насыщенности и ОПП по сравнению с поверхностью спланированного отвала, а также преобладают наиболее устойчивые к химическому воздействию виды (Calamagrostis epigeios, Convolvulus arvensis, Equisetum spp. и др.). В схемах самозарастания отвалов и шлейфов выделяются “вейниковый” и "разнотравный" пути развития, определение которого в каждом конкретном случае зависит от положения участка относительно отвала или террикона и количества токсичных веществ в поверхностных слоях субстрата. Видовой состав древесного яруса в обоих случаях одинаков. Проведение фитомелиорации терриконов значительно ускоряет восстановление растительности, поскольку сформированный культурный фитоценоз по прошествии 1 года соответствует стадии простого фитоценоза при естественном зарастании, которая формируется несколько десятилетий.

\section{СПИСОК ЛИТЕРАТУРЫ}

1. Барабошкина Т.А., Харькина М.А., Жигалин А.Д. Освоение минеральных ресурсов и динамика экологических функций абиотических сфер Земли (на 
примере месторождений Подмосковного буроугольного бассейна) // Бюлл. МОИП. Отд. геол. 2015. Т. 90. Вып. 4. С. 73-80.

2. Воронов А.Г. Геоботаника. Учеб. пособие для унтов и пед. ин-тов. Изд. 2-е. М.: Высш. шк., 1973. $384 \mathrm{c}$.

3. Дамбын $A$. Самовосстановление нарушенных земель в горных разработках Хэнтэйского нагорья Центральной Монголии (на примере Баганурского месторождения угля) // Вест. Бурятского ун-та. 2015. № 4. C. 262-265.

4. Куприянов А.Н., Морсакова Ю.В. Естественное зарастание отвалов Кузбасса // Вест. Кузбасского тех. ун-та. 2006. № 3. С. 48-51.

5. Манаков Ю.А., Куприянов А.Н. Критерии для диагностики первичных стадий сукцессии на отвалах Кузбасса // Горный инф.-аналит. бюл. (науч.-тех. журн.). 2009. Т. 7. № 12. С. 186-193.

6. Миронычева-Токарева Н.П. Сукцессии растительности и динамика растительного вещества при зарастании отвалов лесостепной зоны юга Средней Сибири. Автореф. дис. ... канд. биол. наук. Томск: Ин-т почвоведения и агрохимии СО РАН, 1996. 21 с.

7. Моторина Л.В., Ижевская Т.И. Сравнительная характеристика растительного покрова на отвалах открытых разработок бурого угля и железной руды // Растения и промышленная среда. 1980. № 7. С. 80-87.

8. Стрельникова Т.О., Манаков Ю.А. Особенности флоры отвалов угольных разрезов Кемеровской области // Вест. Томского ун-та. Сер. "Биология". 2010. № 2 (10). C. 44-57.
9. Уланова Н.Г., Белова И.Н., Логофет Д.О. О конкуренции среди популяций с дискретной структурой: матричная модель динамики популяций вейника и березы, растущих совместно // Журн. общей биол. 2008. Т. 69. № 6. С. 441-457.

10. Хомушку Н.Г., Самбуу А.Д. Первичная сукцессия растительности техногенных отвалов Каа-Хемского угольного разреза республики Тыва // Успехи современного естествознания. 2015. № 6. С. 132-136.

11. Чибрик Т.С., Глазырина М.А. Биологическая рекультивация и мониторинг нарушенных промышленностью земель. Учеб. пособие. Екатеринбург: Изд-во УрГУ, 2008. 196 с.

12. Шарапова А.В., Семенков И.Н., Леднев С.А. и др. Саморазвитие горнопромышленных ландшафтов старого района угледобычи в Тульской области // Экология и промышленность России. 2017. Т. 21. № 12. C. $54-59$.

13. Ciesielczuk J., Czylok A., Fabiańska M. J. et al. Plant occurrence on burning coal waste - a case study from the Katowice-Wełnowiec dump, Poland // Environmental \& Socio-economic Studies. 2015. V. 3. № 2. P. 1-10.

14. Lei H., Peng Z., Yigang H. et al. Vegetation and soil restoration in refuse dumps from open pit coalmines // Ecol. Engineering. 2016. V. 94. P. 638-646.

15. Wang J., Wang H., Cao Y., Bai Z., Qin Q. Effects of soil and topographic factors on vegetation restoration in opencast coal mine dumps located in a loess area // Sci. reports. 2016. № 6: 22058. P. 1-11.

\title{
Plant Successions on Coal Mines' Waste Piles in Forest-Steppe of the Tula Oblast
}

\author{
S. A. Lednev ${ }^{1}$, , A. V. Sharapova ${ }^{1}$, I. N. Semenkov ${ }^{1}$, and T. V. Koroleva ${ }^{1}$ \\ ${ }^{1}$ Lomonosov Moscow State University, Faculty of Geography, Moscow, Russia \\ \#e-mail: sled1988@mail.ru
}

\begin{abstract}
The paper describes vegetation successions that can be observed on waste piles of Moscow lignite basin. Characterization of succession are performed with geobotanical descriptions that were made at non-recultivated waste pile, levelled dump and phytomeliorated waste pile. Colonization of coal waste piles by plants corresponds to primary succession that proceeds in specific edaphic conditions. Term and trajectory of this process on waste piles of Moscow lignite basin in the Tula oblast differ at various object types. The rate of revegetation is slowest at slopes of waste piles and levelled spoils, where only solitary individuals of ruderal species can occur. At levelled spoils' surfaces and self-developing deluvial-proluvial foreslopes (which is forming at waste pile foot) pioneer plant groups, simple structured phytocoenoses and complex structured phytocoenoses are discovered. Most common tree species in simple structured and complex structured communities is Betula pendula. Under the toxic flow influence herbaceous layer at deluvial-proluvial foreslopes and in certain parts of levelled spoil consists mainly of Calamagrostis epigeios, Equisetum spp., Convolvulus arvensis. Out of toxic flow influence at levelled spoil forb meadows with large proportion of legumes (Trifolium hybridum, Lotus corniculatus, Melilotus albus etc.) occur. Succession stages changing is not rapid and revegetation processes takes decades; the phytomelioration of Moscow lignite basin waste piles in the Tula oblast can speed this process up by overcoming the delayed pioneer plant groups stage. The pattern of plant succession trajectories on waste piles of Moscow lignite basin in forest-steppe landscapes of the north part of the Central Russian Upland was developed.
\end{abstract}

Keywords: revegetation, primary succession, coal waste piles, anthropogenic ecosystems, plant communities, waste piles recultivation 


\section{REFERENCES}

1. Baraboshkina T.A., Kharkina M.A., Zhigalin A.D. Development of mineral resources and dynamics of ecological functions of abiotic spheres of Earth (on the example of fields of Moscow brown-coal basin). Byull. MOIP. Otd. Geol., 2015, vol. 90, no. 4, pp. 73-80. (In Russ.).

2. Voronov A.G. Geobotanika [Geobotany]. Moscow: Vyssh. Shkola Publ., 1973, 2 ed. 384 p.

3. Dambyn A. Selfrestoration of spoiled lands in mountain mining areas Khentey upland of Central Mongol (Baganur brown coal deposit). Vestn. Buryat. Gos. Univ., 2015, no. 4, pp. 262-265. (In Russ.).

4. Kupriyanov A.N., Morsakova Yu.V. Natural revegetation of Kuzbass waste dumps. Vestn. Kuzbass. Gos. Tekh. Univ., 2006, no. 3, pp. 48-51. (In Russ.).

5. Manakov Yu.A., Kupriyanov A.N. Criteria for diagnosing the primary stages of succession on the Kuzbass waste dumps. Gornyi Inf.-Analit. Byull., 2009, vol. 7, no. 12, pp. 186-193. (In Russ.).

6. Mironycheva-Tokareva N.P. Successions of vegetation and the dynamics of phytomass during the revegetation of the dumps of the forest-steppe zone in the south of Central Siberia. Extended Abstract of Cand. Sci. (Biol.) Dissertation. Tomsk: Inst. Soil Sci. Agrochem., Siber. Branch Acad. Sci., 1996. 21 p.

7. Motorina L.V., Izhevskaya T.I. Comparative characteristics of vegetation on the dumps of opencast mining of brown coal and iron ore. Rast. Prom. Sreda, 1980, no. 7, pp. 80-87. (In Russ.).

8. Strel'nikova T.O., Manakov Yu.A. Features of coal mines dumps flora of Kemerovo region. Vestn. Tomsk.
Gos. Univ., Ser. Biol., 2010, no. 2(10), pp. 44-57. (In Russ.).

9. Ulanova N.G., Belova I.N., Logofet D.O. On the competition among discrete-structured populations: a matrix model for population dynamics of woodreed and birch growing together. Zh. Obshchei Biol., 2008, vol. 69, no. 6, pp. 441-457. (In Russ.).

10. Khomushku N.G., Sambuu A.D. Primary succesion of the vegetation to overgrown of the Kaa-Khem coal-katens in Tuva. Usp. Sovrem. Estestvozn., 2015, no. 6, pp. 132-136. (In Russ.).

11. Chibrik T.S., Glazyrina M.A. Biologicheskaya rekul'tivatsiya i monitoring narushennykh promyshlennost'yu zemel' [Biological Reclamation and Monitoring of Lands Disturbed by Industrial Activity]. Yekaterinburg: Ural. Gos. Univ., 2008. 196 p.

12. Semenkov I.N., Lednev S.A., Karpachevsky A.M., Koroleva T.V. Self-development of mining landscapes of the old coal mining district in Tula region. Ecology and Industry of Russia, 2017, vol. 21, no. 12, pp. 54-59. (In Russ.). doi: 10.18412/1816-0395-2017-12-54-59.

13. Ciesielczuk J., Czylok A., Fabiańska M.J., Misz-Kennan M. Plant occurrence on burning coal waste - a case study from the Katowice-Wełnowiec dump, Poland. Environ. Socio.-Econ. Stud., 2015, vol. 3, no. 2, pp. 1-10.

14. Lei H., Peng Z., Yigang H., Yang Z. Vegetation and soil restoration in refuse dumps from open pit coalmines. Ecol. Eng., 2016, vol. 94, pp. 638-646.

15. Wang J., Wang H., Cao Y., Bai Z., Qin Q. Effects of soil and topographic factors on vegetation restoration in opencast coal mine dumps located in a loess area. Sci. Rep., 2016, no. 6: 22058. doi 10.1038/srep22058 